\title{
Determination of normal splenic volume in relation to age, gender and body habitus: a stereological study on computed tomography
}

\author{
V. Caglar ${ }^{1}$, O.A. Alkoc ${ }^{2}$, R. Uygur ${ }^{1}$, O. Serdaroglü ${ }^{3}$, O.A. Ozen ${ }^{1}$ \\ ${ }^{1}$ Department of Anatomy, Faculty of Medicine, Namık Kemal University, Tekirdag, Turkey \\ ${ }^{2}$ Department of Anatomy, Faculty of Medicine, Istanbul Medeniyet University, Istanbul, Turkey \\ ${ }^{3}$ Department of Radiology, Corlu Sifa Hospital, Tekirdag, Turkey
}

[Received 11 March 2014; Accepted 31 March 2014]

\begin{abstract}
Background: The aim of this study is to assess and document the dimensions of the normal spleen measured on computed tomography (CT) images with the normal splenic volume measured by Cavalieri principle on CT images and thereby serve as a baseline for comparison in cases of splenomegaly using abdominal CT. To investigate the relationship between these changes and body mass index, gender, abdominal diameters.

Materials and methods: We retrospectively reviewed abdominal CT examinations of 212 adults between the ages of 20 and 88 years. There were seven groups of patients. The spleen volume (SV) measurements using abdominal CT images of each patient on the Image Information Systems were performed with Cavalieri principle. Results: The mean SV and splenic length (SL), width (SW), and thickness (ST) for the total study population of 212 patients was $198 \pm 88 \mathrm{~cm}^{3}, 9.96 \pm 2.1 \mathrm{~cm}, 8.87 \pm$ $\pm 1.6 \mathrm{~cm}$ and $4.58 \pm 0.8 \mathrm{~cm}$, respectively. There was a strong correlation between SV and ST $(r=0.752, p<0.001), S L(r=0.735, p<0.001)$, SW $(r=0.681$, $p<0.001)$ mean values of total study population. Comparison between mean splenic dimension parameters for males and females showed a statistically significant difference ( $p=0.032$ for SV, $p=0.04$ for ST) but no statistically significant difference with $S L$ and SW. Also there was a positive correlation between SV and body height, sagittal abdominal diameter and transvers abdominal diameter in mean of total groups and female groups, there was no correlation in males.

Conclusions: The normal reference ranges for SV and size given in this study can serve as a standard to judge whether splenomegaly is present in patients. (Folia Morphol 2014; 73, 3: 331-338)
\end{abstract}

Key words: splenic volume, splenic size, computed tomography, stereology

\section{INTRODUCTION}

The spleen is an intraperitoneal organ situated in the upper left quadrant of the abdominal cavity be- tween the fundus of the stomach and the diaphragm. It is the largest organ in the reticuloendothelial system (RES). The characteristics of abdominal organ volumes

Address for correspondence: Dr V. Caglar, Department of Anatomy, Namık Kemal University Faculty of Medicine, Tekirdag, 59100 Turkey, tel: +90 507387 7279, +90 282250 5523, telefax: +90 28225099 28, e-mail: vcaglar32@hotmail.com

The manuscript has been presented in a congress ( $15^{\text {th }}$ National Congress of Anatomy) as a poster at September 05-08, 2013, Samsun, Turkey. 
and sizes have potential clinical importance. Changes in the size and volume of the organs may be related to many diseases. For example, splenomegaly is a well-known manifestation of some diseases that may include the liver, hematopoietic system, and immune system [30, 31]. In addition, splenic enlargement can be the result of a number of disorders, such as infections, storage and connective tissue diseases and malignant conditions. Splenic atrophy also occurs in adult coeliac disease [28]. Accurate assessment of spleen volume (SV) is used in the clinical treatment of patients with these diseases.

It has been a standard practice for years to use splenic size (SS) as an indicator of disease activity in a variety of disorders of the RES. In order to detect changes in the size and volume of an organ, normal anatomic values should be known. Comparisons of these values between organs produce data that can be used for diagnosing specific diseases. These data allow the clinician to identify the grade of atrophy or hypertrophy of an organ. A detailed knowledge of age related structural changes in the spleen is necessary for diagnosis of pathological processes and differentiating these from normal variants. Spleen size of healthy subjects in relevant age group should be known in order to decide whether the image of spleen on computed tomography (CT) is normal or not. Previously used techniques for measuring the SV and SS have relied on sonography $[22,27,30]$, CT $[2,11,12,23]$ and cadaveric studies $[5,7,19]$. $C$ is known to be a reliable and accurate method for assessing volumes and sizes of the spleen, pancreas, kidney and other intraabdominal organs $[3,9,12,24]$. There are previously published studies documenting normal SV and SS in adult populations $[9,12,24]$. However, these studies have some limitations: the study populations were often heterogeneous and the individual sample sizes were small or participants did not have a healthy spleen. Furthermore, there are no studies specifically designed to evaluate special populations, such as adults grouped into decades. The aim of this study is to assess and document the normal SS measured on $\mathrm{CT}$ images with the normal SV measured by Cavalieri principle on $\mathrm{CT}$ images and thereby serve as a baseline for comparison in cases of splenomegaly.

\section{MATERIALS AND METHODS}

This study conformed to Helsinki Declaration and ethics committee with protocol number 2013.68.05.17 approval was obtained at our institution.

\section{Subject selection}

The SV was retrospectively calculated by applying Cavalieri principle to CT scans of 212 adult patients referred for abdominal $\mathrm{CT}$ for various reasons. The radiologist's report for each CT examination was reviewed. Patients with previous splenectomy, difficult identification of splenic margins, splenic tumours, and focal lesions were excluded from the study. There were 107 males and 105 females, whose age ranged from 20 to 88 years. All studies were obtained with a single-detector row helical scanner (Tomoscan AV, Philips). Abdominal CT images (section thickness $5 \mathrm{~mm}$ ) were examined retrospectively. Patients were categorised in six age groups (20-30, 31-40, 41-50, $61-70,71-80$, and 81-88). The number of patients was insufficient in 51-60 group, so this group of patients was excluded from the study. Demographic information such as gender, age, body weight $[\mathrm{kg}]$ and height $[\mathrm{m}]$ of each patient were recorded at the time of their CT scans. The average age of the patients was $51 \pm 20$ years, height $166 \pm 8 \mathrm{~cm}$ (between 147 and $190 \mathrm{~cm}$ ), body weight $73 \pm 14 \mathrm{~kg}$ (between 40 and $120 \mathrm{~kg}$ ). Body mass index (BMI: body weight $[\mathrm{kg}] /$ height $\left[\mathrm{m}^{2}\right]$ average $25 \pm 5 \mathrm{~kg} / \mathrm{m}^{2}$ (between 15 and 44).

\section{Stereological estimation of the volume of the spleen}

The SV measurements using abdominal CT images of each patient on the Image Information Systems (K-PACS Patient CD) (London, United Kingdom) were performed with Cavalieri principle. Organ volumes can be estimated using the Cavalieri principle and consecutive serial tissue sections [6]. A point counting grids (PCG) was used to estimate the area of each section of spleen. The point density of the PCG was designed to obtain an appropriate coefficient of error (CE) for the serial sections [21]. A square grid system with $d=0.5 \mathrm{~cm}$ was placed randomly on each transverse section CT images of spleen and the points hitting the surface area of spleen were counted for each section (Fig. 1). Counting procedure was performed 3 times for each image of a cross-section and averages of these counts were recorded. Points corresponding to the boundaries of the spleen area were included in the count. Other points outside the boundaries, even if they were very close, were not included in the count. The SV measurements were performed 3 times for each patient. Mean values of 3 measurements were calculated for SV. Calculations 


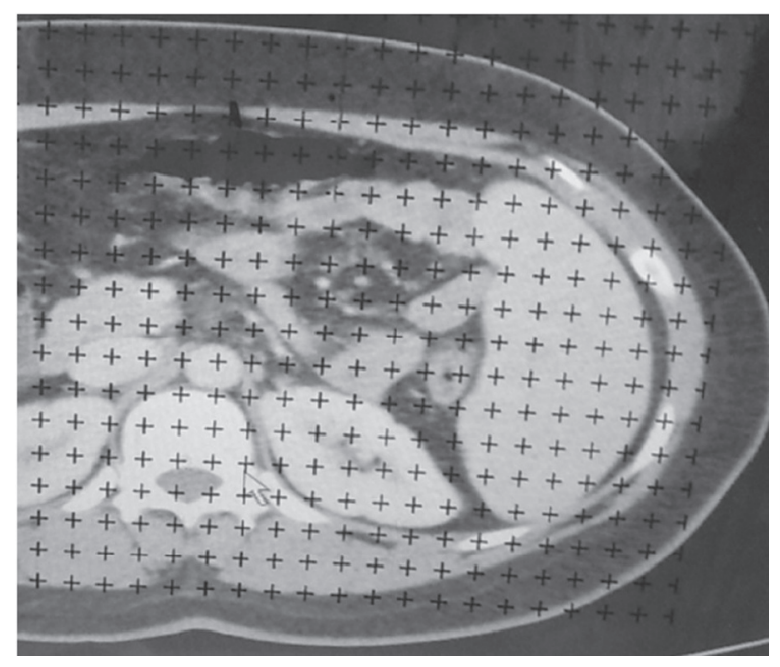

Figure 1. A spleen slice section in axial plane, a point counting grid superimposed on the computed tomography scan.

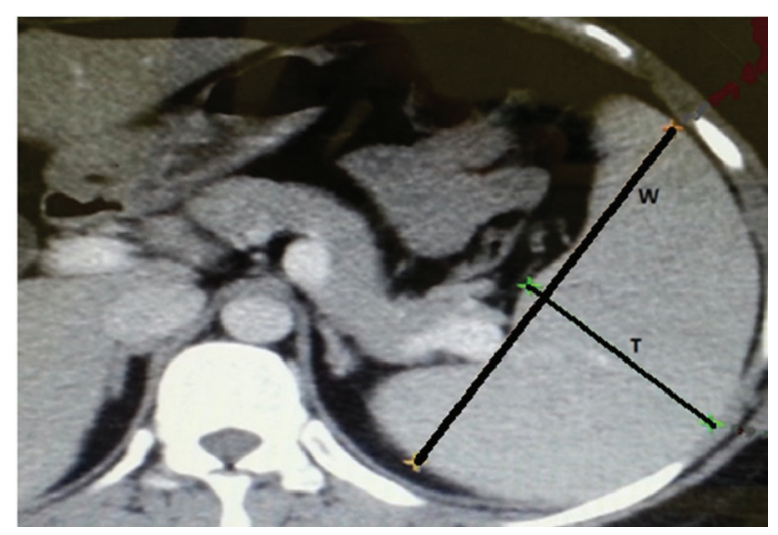

Figure 2. Example of measurement of largest width (W) of spleen, greatest thickness at section where $\mathrm{W}$ was determined $(\mathrm{T})$.

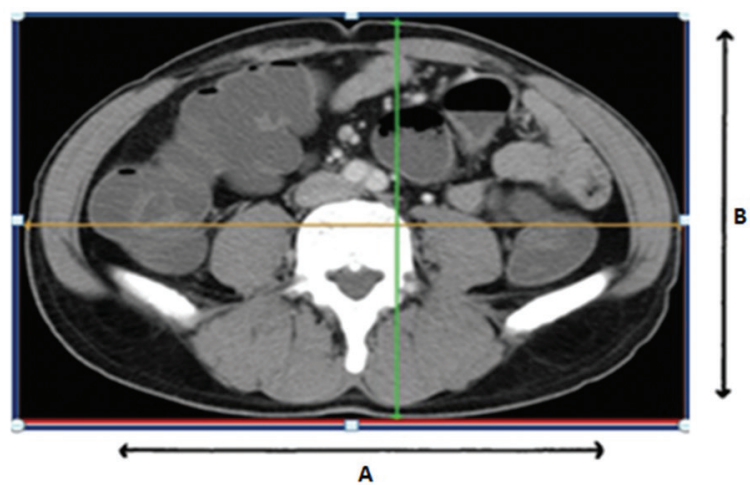

Figure 3. Anthropometric measurements obtained from computed tomography registrations; transverse abdominal diameter $(A)$, sagittal abdominal diameter (B).

of the SV, CE of the estimates and other related data processing were done using a spreadsheet program
(Microsoft Excel 97). After initial setup and preparation of the formula, the point counts and other data were entered for each SV and results were obtained automatically.

$$
\mathrm{V}=\mathrm{t} \times[(\mathrm{SU} \times \mathrm{d}) / \mathrm{SL}]^{2} \times \sum \mathrm{P}
$$

where ' $t$ ' is the sectioning interval for $n$ number of consecutive sections, 'SU' is the scale unit of the printed film, ' $d$ ' is the distance between the test points of the grid, 'SL' is the length of the scale on the CT images and ' $\sum \mathrm{P}$ ' is the total number of points hitting the section cut surface areas of the spleen $[3,21]$.

\section{Anthropometric measurements of spleen}

The measurement of SS were recorded for every patient on the transverse CT images, including the splenic length (SL), width (SW), and thickness (ST), as described previously. The SL was obtained by multiplying the number of sections where the spleen was visualised by the thickness of the sections. For instance, if the spleen was seen in 20 contiguous cross sectional images with $5 \mathrm{~mm}$ thickness, the SL was recorded as $10 \mathrm{~cm}$. The SW was measured as the greatest overall dimension of the spleen. The ST was recorded as the greatest thickness at the section where SW was determined (Fig. 2) [2, 31].

On CT images, sagittal abdominal diameters (SAD) were measured as the distance between the anterior and posterior skin on one cross-sectional scan obtained at the level of the fourth lumbar vertebra. The transverse abdominal diameters (TAD) were measured at the same level again, as the distance between bilateral skin (Fig. 3) [3, 18].

\section{Statistical analysis}

All statistical analyses were performed using the SPSS 11.0 for Windows and Microsoft Excel 2003 for Windows. Subject characteristics and results were reported as mean \pm standard deviation. The variances of the groups (homogeneity) were assessed by Levene's test. The paired t test or Mann-Whitney $U$ test and ANOVA or Kruskal-Wallis $\mathrm{H}$ test was used to analyse the groups. Duncan test was used to compare group means. Correlation was determined using the Pearson correlation coefficient. Differences were considered significant if two-tail p values were less than 0.05 .

\section{RESULTS}

In our study, the mean CE was estimated as $1.2 \%$. Patient demographic information, SV, SS and other parameters were summarised in Table 1. 
Table 1. Characteristics of subjects enrolled in computed tomography imaging studies of the spleen

\begin{tabular}{lcccc}
\hline Parameters & Total & Female & Male & P* \\
\hline $\mathrm{N}$ & 212 & 105 & 107 & NS \\
Age [years] & $51 \pm 20$ & $50 \pm 19$ & $53 \pm 20$ & $<0.001$ \\
Height $[\mathrm{cm}]$ & $166 \pm 8$ & $161 \pm 5$ & $170 \pm 7$ & $<0.001$ \\
Weight $[\mathrm{kg}]$ & $73 \pm 14$ & $70 \pm 15$ & $77 \pm 12$ & 0.002 \\
BMI $\left[\mathrm{kg} / \mathrm{m}^{2}\right]$ & $25 \pm 5$ & $27 \pm 5$ & $23 \pm 3$ & 0.032 \\
SV $\left[\mathrm{cm}^{3}\right]$ & $198 \pm 88$ & $184 \pm 84$ & $210 \pm 90$ & NS \\
SL $[\mathrm{cm}]$ & $9.96 \pm 2.1$ & $9.7 \pm 2.1$ & $10.1 \pm 2.1$ & NS \\
SW $[\mathrm{cm}]$ & $8.87 \pm 1.6$ & $8.9 \pm 1.7$ & $8.8 \pm 1.6$ & 0.04 \\
ST $[\mathrm{cm}]$ & $4.58 \pm 0.8$ & $4.4 \pm 0.9$ & $4.7 \pm 0.8$ & NS \\
SAD $[\mathrm{cm}]$ & $22.4 \pm 6$ & $22 \pm 4$ & $23 \pm 3$ & NS \\
TAD $[\mathrm{cm}]$ & $33.6 \pm 4$ & $33 \pm 4$ & $33 \pm 3$ & \\
\hline
\end{tabular}

Values are means \pm standard deviation; * $p$ value shows comparison of men and women; NS — non significant ( $p>0.05)$; BMI — body mass index; SV — splenic volume; SW — splenic weight; $\mathrm{SL}$ — splenic length; ST — splenic thickness; SAD — sagittal abdominal diameter; TAD — transverse abdominal diameter

Table 2. Relationship between the parameters used and splenic volume

\begin{tabular}{|c|c|c|c|c|c|c|}
\hline \multirow[t]{3}{*}{ Parameters } & \multicolumn{6}{|c|}{ Splenic volume } \\
\hline & \multicolumn{2}{|c|}{ Total $(n=212)$} & \multicolumn{2}{|c|}{ Female $(n=105)$} & \multicolumn{2}{|c|}{ Male $(n=107)$} \\
\hline & $r$ & $\mathbf{p}$ & $r$ & $\mathbf{p}$ & $r$ & $\mathbf{p}$ \\
\hline Age [years] & -0.212 & 0.002 & -0.110 & 0.001 & -0.328 & 0.001 \\
\hline Height [cm] & 0.218 & 0.001 & 0.222 & 0.023 & 0.211 & 0.03 \\
\hline Weight [kg] & 0.288 & $<0.001$ & 0.349 & $<0.001$ & 0.178 & $<0.047$ \\
\hline BMI $\left[\mathrm{kg} / \mathrm{m}^{2}\right]$ & 0.212 & 0.003 & 0.287 & 0.003 & NS & \\
\hline $\mathrm{SL}[\mathrm{cm}]$ & 0.735 & $<0.001$ & 0.765 & $<0.001$ & 0.705 & $<0.001$ \\
\hline $\mathrm{SW}[\mathrm{cm}]$ & 0.681 & $<0.001$ & 0.695 & $<0.001$ & 0.691 & $<0.001$ \\
\hline ST [cm] & 0.752 & $<0.001$ & 0.743 & $<0.001$ & 0.756 & $<0.001$ \\
\hline $\mathrm{SAD}[\mathrm{cm}]$ & 0.227 & 0.001 & 0.226 & 0.021 & NS & \\
\hline $\mathrm{TAD}[\mathrm{cm}]$ & 0.204 & 0.003 & 0.283 & 0.003 & NS & \\
\hline
\end{tabular}

Values are means \pm standard deviation; $r$ - value is the correlation coefficient; $p$ - value is the probability; NS — non significant $(p>0.05)$; rest abbreviations as in Table 1

\section{Splenic volume, age and gender}

The mean SV for the total study population of 212 patients was $198 \pm 88 \mathrm{~cm}^{3}$. The SV ranged from 61 to $562 \mathrm{~cm}^{3}$. The SV in total and male population changes slightly during 20-50 years of age; in female population SV changes slightly during 20-70 years of age and then declines thereafter. The SV reaches a maximum point in the fifth decade $\left(221 \pm 95 \mathrm{~cm}^{3}\right)$ and SV reaches a minimum point in the ninth decade $\left(159 \pm 56 \mathrm{~cm}^{3}\right)$ in total population. There was a general decrease in SV as age increased. There was a significant negative correlation between SV and age for total study population $(r=-0.212, p=0.002)$, and female $(r=-0.110, p=0.001)$ and male groups $(r=-0.328, p=0.001)$ (Table 2$)$. The ranges for the
SV across decades in total study opulation and male and female groups are shown in Tables 3, 4 and 5.

The average SV was higher in males $\left(210 \pm 90 \mathrm{~cm}^{3}\right)$ than in females $\left(184 \pm 84 \mathrm{~cm}^{3}\right)$. There was statistically significant difference between the SV of male patients and that of female patients in this study $(p=0.032$ ). In our study, the mean age for males was 3 years higher than the mean age for females and the difference was not statistically significant. This result shows the effect of gender on the SV.

\section{Splenic volume and dimensions}

The mean SL, SW, and ST for the total study population of 212 patients was $9.96 \pm 2.1$ (range 4.8$-15.5) \mathrm{cm}, 8.87 \pm 1.6$ (range $4.9-12.4$ ) cm and 
Table 3. Pancreatic volume are shown for each decade in total group

\begin{tabular}{lccccc}
\hline Age [years] & $\mathbf{N}$ & SV [cm $\left.{ }^{3}\right]$ & SW [cm] & SL [cm] & ST [cm] \\
\hline $20-30$ & 39 & $201 \pm 65$ & $8.5 \pm 1.5$ & $10.5 \pm 1.8$ & $4.6 \pm 0.8$ \\
$31-40$ & 37 & $219 \pm 98$ & $9 \pm 1.6$ & $10.1 \pm 2$ & $4.6 \pm 0.8$ \\
$41-50$ & 39 & $221 \pm 95$ & $9.7 \pm 1.7$ & $10.5 \pm 2.4$ & $4.7 \pm 0.8$ \\
$61-70$ & 38 & $197 \pm 101$ & $9 \pm 1.4$ & $9.6 \pm 2.2$ & $4.6 \pm 1$ \\
$71-80$ & 38 & $171 \pm 77$ & $8.4 \pm 1.7$ & $9.2 \pm 2$ & $4.4 \pm 0.9$ \\
$81-88$ & 21 & $159 \pm 56$ & $7.9 \pm 1.2$ & $8.9 \pm 1.5$ & $4.4 \pm 0.8$ \\
\hline
\end{tabular}

Values are means \pm standard deviation; abbreviations as in Table 1

Table 4. Splenic volume are shown for each decade in male group

\begin{tabular}{lccccc}
\hline Age [years] & $\mathbf{N}$ & SV $\left[\mathrm{cm}^{3}\right]$ & SW $[\mathrm{cm}]$ & SL $[\mathrm{cm}]$ & ST $[\mathrm{cm}]$ \\
\hline $20-30$ & 18 & $226 \pm 68$ & $8.9 \pm 1.4$ & $10.8 \pm 1.4$ & $4.7 \pm 0.5$ \\
$31-40$ & 19 & $241 \pm 91$ & $9.2 \pm 1.7$ & $10.6 \pm 1.5$ & $4.8 \pm 0.9$ \\
$41-50$ & 18 & $249 \pm 104$ & $9.7 \pm 2$ & $11.1 \pm 2.3$ & $4.8 \pm 0.9$ \\
$61-70$ & 19 & $191 \pm 110$ & $8.5 \pm 1.4$ & $9.3 \pm 2.2$ & $4.5 \pm 0.8$ \\
$71-80$ & 18 & $184 \pm 60$ & $8 \pm 1.2$ & $9.5 \pm 1.7$ & $4.7 \pm 0.8$ \\
$81-88$ & 15 & $162 \pm 69$ & $8.2 \pm 1.2$ & $9.2 \pm 2.5$ & $4.5 \pm 0.8$ \\
\hline
\end{tabular}

Values are means \pm standard deviation; abbreviations as in Table 1

Table 5. Splenic volume are shown for each decade in female group

\begin{tabular}{lccccc}
\hline Age [years] & $\mathbf{N}$ & SV $\left[\mathrm{cm}^{3}\right]$ & SW [cm] & SL $[\mathrm{cm}]$ & ST [cm] \\
\hline $20-30$ & 21 & $174 \pm 52$ & $9.1 \pm 1.8$ & $9.5 \pm 2.2$ & $4.6 \pm 0.9$ \\
$31-40$ & 19 & $194 \pm 88$ & $8.9 \pm 1.6$ & $10.4 \pm 2$ & $4.4 \pm 0.8$ \\
$41-50$ & 20 & $202 \pm 96$ & $9.6 \pm 1.4$ & $9.9 \pm 2.3$ & $4.5 \pm 0.8$ \\
$61-70$ & 19 & $203 \pm 95$ & $8.9 \pm 1.2$ & $10 \pm 2.1$ & $4.6 \pm 1.1$ \\
$71-80$ & 20 & $159 \pm 90$ & $8.3 \pm 2$ & $9 \pm 2.2$ & $4.1 \pm 0.8$ \\
$81-88$ & 6 & $151 \pm 18$ & $7.1 \pm 0.9$ & $9.4 \pm 1$ & $3.9 \pm 0.6$ \\
\hline
\end{tabular}

Values are means \pm standard deviation; abbreviations as in Table 1

$4.58 \pm 0.8$ (range $2.6-6.9$ ) $\mathrm{cm}$, respectively. The SL, SW, and ST measurements for male and female groups are shown in Table 1. The SS in total study population and male and female groups changes slightly during 20-50 years of age, and then declines thereafter. The SL, SW, and ST reach a maximum point in the fifth decade in total population $(10.5 \mathrm{~cm}$, $9.7 \mathrm{~cm}, 4.7 \mathrm{~cm}$, respectively) (Table 3).

Comparison between mean SS parameters for males and females (from unpaired t-test determination) showed a statistically significant difference $(p=0.04$ for ST) but no statistically significant difference with SW and SL. There was a strong correlation between SV and ST $(r=0.752, p<0.001)$, SL $(r=0.735, p<$ $<0.001)$, SW $(r=0.681, p<0.001)$ in mean values of total study population. The SL, SW and ST correlations for male and female groups are shown in Table 2.

\section{Splenic volume and body habitus}

The mean body weight of the patients was $73 \pm$ $\pm 14 \mathrm{~kg}$ and the height was $166 \pm 8 \mathrm{~cm}$. A moderate correlation was observed between the SV and the 
body weight and height of the subjects $(r=0.288$, $p<0.001$ and $r=0.218, p=0.001$, respectively). On average, the SV increases with an increase in body weight and height.

The BMI was $25 \pm 5 \mathrm{~kg} / \mathrm{m}^{2}$ for the total study population. The BMI for male patients was $23 \pm 3 \mathrm{~kg} / \mathrm{m}^{2}$ and that for female patients was $27 \pm 5 \mathrm{~kg} / \mathrm{m}^{2}$. There was statistically significant difference between the BMI of male patients and that of female patients in this study $(p=0.002)$. A statistically significant relationship was observed between the SV and BMI $(r=0.212, p=0.003)$.

The SAD was $22.4 \pm 6 \mathrm{~cm}$ for the total study population. The SAD for male patients was $23 \pm 3 \mathrm{~cm}$ and that for female patients was $22 \pm 4 \mathrm{~cm}$. The TAD was $33.6 \pm 4 \mathrm{~cm}$ for the total study population. The $S A D$ for male and female patients was $33 \mathrm{~cm}$. There was no statistically significant difference between the SAD and TAD of male and female patients in this study ( $p>0.05$ ) (Table 2 ).

\section{DISCUSSION}

In the present study, we examined the range of SV and SS in patients and the relationship between SS and parameters such as age, height, weight, BMI, gender, SAD, TAD. The SV and SS varies from person to person. Besides, a number of disorders are accompanied by altered SS, including liver disease, portal hypertension, splenic vein thrombosis, lymphoma and other neoplastic processes, and haematologic entities [31]. In addition, chronic formaldehyde exposure can cause morphometric alterations in the follicles and marginal zone of the spleen [10]. Assessment of SV and SS without radiologic examination is subjective and known to be inaccurate $[26,31]$, therefore evaluation with radiologic imaging is common. The use of imaging techniques is receiving increasing attention to estimate SV and SS, particularly for diagnosis of and follow-up of splenomegaly. Current literature recommends that $\mathrm{CT}$ can identify changes in SV and SS with the highest sensitivity and specificity $[2,31]$. Several reports have demonstrated differences in the SV and SS in CT, magnetic resonance imaging, sonography and autopsy $[2,5,16,26,31]$. Many researchers attempted to estimate the SS by using "splenic indices" which are calculated using SL, ST and SW. Several studies in adult population have shown significant imaging accuracy based on the type of indices used to denote splenic enlargement $[2,23,31]$. However, several of the indices used are time- and effort-consuming and require significant calculation, therefore there is a need for a simpler and more practical method to determine the SV and SS. We estimated SV and SS in healthy adults grouped according to age. We also examined the relationship with parameters such as body weight and height which may have effect on SV and SS.

The SV inversely correlated with age $(r=-0.212$, $p=0.002)$. This finding is supported by previous studies $[11,15,16,20]$. This study has shown that SV and SS increases slightly during 20-50 years of age and then declines thereafter. The decline in $\mathrm{SV}$ is more gradual later in life. We found that the mean $\mathrm{SV}$ values were $198 \pm 88$ (range $61-562) \mathrm{cm}^{3}$ for the total study population, $184 \pm 84$ (range 70-462) $\mathrm{cm}^{3}$ for females and $210 \pm 90$ (range $61-562) \mathrm{cm}^{3}$ for males. The SV is affected by both age and body habitus. Based on the results obtained, splenomegaly or splenic atrophy can be defined as SV that is according to the normal ranges given in decades.

Schulz et al. [29] based on CT studies found mean SV of $169 \mathrm{~mL}$. Ehimwenma and Tagbo [8] reported that average SV was $202 \pm 49 \mathrm{~cm}^{3}$ in 91 male individuals (mean age 32 years) and $153 \pm 33 \mathrm{~cm}^{3}$ in $109 \mathrm{fe}$ male individuals (mean age 29 years). In our study, we found that the mean SV of males in the fourth decade (range 31-40 years of age) was $241 \mathrm{~cm}^{3}$ and females in the third decade (range 20-30 years of age) $174 \mathrm{~cm}^{3}$. Geraghty et al. [9] found the mean SV of $209 \mathrm{~cm}^{3}$ in 149 individuals. Hoefs et al. [13] used CT and found a normal SV of $201 \mathrm{~mL}$ in 11 normal patients. Prassopoulos et al. [24] reported a mean SV of $214.6 \mathrm{~cm}^{3}$ in 140 individuals. Henderson et al. [12] reported a normal SV $219 \mathrm{~cm}^{3}$ as calculated from axial CT acquisitions. Our results are very similar to those in literature mentioned above. Differences in SV and SS may be due to differences of the number, mean age and gender of individuals enrolled in the study and perhaps regional variations between populations studied.

Kaneko et al. [16] reported a mean SV of $112 \pm$ $\pm 40 \mathrm{~cm}^{3}$ for 150 healthy volunteers Japanese patients, and $123 \pm 45 \mathrm{~cm}^{3}$ in 238 Japanese patients in another study [15]. Harris et al. [11] found the mean SV to be $127.4 \pm 62.9 \mathrm{~cm}^{3}$ for the 230 Japanese patients. A lower SV is expected than in studies which incorporate a predominantly Japanese population. The difference between the average SV in the Japanese populations could be due to the difference in the age range or the body habitus of the patients studied.

Normal cadaveric SV reported by Loftus et al. [19] are a mean volume of $110 \mathrm{~cm}^{3}$ and Chowdhury et al. [5] 
reported that mean SV in male was $75 \pm 3 \mathrm{~mL}$, and in female was $60 \pm 4 \mathrm{~mL}$. These values are consistently smaller than those reported here. We think that autopsy studies are insufficient to explain the relation between spleen and age because of the small number of cases, lack of a classification for age groups and absence of clinical history with regard to splenic pathologies.

In our study, mean SV is greater in males than it is in females by $11.4 \%$. This result is compatible with other studies on SV $[9,11]$. Sex difference in mean ST was found to be significant except for SL and SW. As there were correlations between SL, SW and ST and both height and weight, we would expect a larger average SS in men on the basis of their larger body size. In our study, mean SS are greater in males than it is in females. Hosey et al. [14], in a study of a healthy collegiate athletic population, found that SS was larger in men than in women. Harris et al. [11] reported that the average SV was higher in males than in females. In our study, we observed that SV and ST were higher in male than in female and the difference was statistically significant. The SL and SW were higher in male than in female but the difference was not statistically significant.

Ehimwenma and Tagbo [8] reported that there was no statistically significant correlation between age of subjects and SL, SW, or SV. In this study we found that there was statistically significant negative correlation between age of subjects and SL, SW and SV, except ST. This finding is supported by previous studies $[15,16]$.

The presence of a significant relationship between $\mathrm{BMI}$ and SV suggests an effect of obesity on the SV. The previous studies indicated that splenomegaly occurred in obese patients [25]. In our study, there was a positive correlation between the SV and BMI. This is also supported by the study of Altunkaynak et al. [1] who reported that high fat diet caused splenomegaly via sinusoidal dilatation and intra-cellular or intercellular deposits.

Since SAD and TAD is considered a good indicators of the amount of body fat, we examined the relationship between SAD, TAD and the SV. There was a positive correlation between $S V$ and SAD and TAD in mean of total study population and female group, there was no such correlation in males. Therefore, we consider that our data about the relationship between SV and diameters is unreliable for an approximate estimation of SV.

Organ size is usually associated with subject height and weight [7]. We found a significant correlation between SV and subject height, weight, and BMI. Okoye et al. [22] and Spielman et al. [30] reported good cor- relation between SS and subject height and weight. Moreover, Okoye et al. [22] and Spielman et al. [30] found strong correlation between subject height and SL. Other studies demonstrating the relationship between the SS and subject height and weight are also available $[14,19]$. As there were correlations between SS and both subject height and weight, we would expect a larger average SV and SS in men on the basis of their larger body size.

The measurement of $S \mathrm{~L}$ in routine clinical practice is a very good indicator of actual SS $[19,23,27]$. But it was not clear to what extent these measurements reflected the actual SL. There is variation among radiological texts in defining the upper limits of normal for longitudinal diameter, with values ranging from 12 to $14 \mathrm{~cm}$ in adults [14]. Some studies suggested an average $S L$ of $12 \mathrm{~cm}$, average SW of $5 \mathrm{~cm}$, and average ST of $7 \mathrm{~cm}[19,22$, 26]. For daily routine, a value of $10 \mathrm{~cm}$ could also be used as the upper limit of normality for the SL [2]. Hosey et al. [14] reported that mean SL was $10.65 \mathrm{~cm}$ for 631 subjects. Capaccioli et al. [4] found a mean SL of $10.5 \mathrm{~cm}$ in a population of 180 Italian adults, without stratifying for age. Bezzera et al. [2] found maximum SL of $9.7 \mathrm{~cm}$ as the upper limit of normality in United States volunteers. Our average for $S L$ of $9.96 \mathrm{~cm}$ is consistent with previous normal values reported for the general adult population. These observations suggest that there is no significant racial bias of SL.

Bezerra et al. [2] reported that there was a strong correlation between SV and SL, also SL and SW had the best correlation indices. Konus et al. [17] found that there was a strong correlation between SV and length. In a similar study by Prassopoulos and Cavouras [23] in children, correlating individual measures to the SV founded the ST. In our study there was a correlation between SV and SL, SW, ST, particularly SL had the best correlation. This study shows that a single simple SL measurement in CT gives clinically useful indication of true SS. This finding supports the historical assessment of splenomegaly based on SL.

In summary, our results define normative values for SV and SS for adult population by stratifying for age. This dataset may prove useful in future research to identify the natural course of SV and SS followed by normalisation in adult population with splenomegaly and atrophic spleen.

\section{CONCLUSIONS}

The SV in adult population continues to increase during 20-50 years of age, and then declines there- 
after. The SV significantly correlates with age, subject height and weight, and body habitus. The SV may be estimated using formulae in the clinical setting, provided that basic information such as SS, patient age, body weight and height are known. The normal reference ranges for SV and SS given in this study can serve as a standard to judge whether splenomegaly is present in patients.

\section{REFERENCES}

1. Altunkaynak BZ, Özbek E, Altunkaynak ME (2007) A stereological and histological analysis of spleen on obese female rats, fed with high fat diet. Saudi Med J, 28: 353-357.

2. Bezerra AS, D'Ippolito G, Faintuch S, Szejnfeld J, Ahmed M (2005) Determination of splenomegaly by CT: is there a place for a single measurement? AJR, 184: 1510-1513.

3. Caglar V, Songur A, Yagmurca M, Acar M, Toktas M, Gonul Y (2012) Age-related volumetric changes in pancreas: a stereological study on computed tomography. Surg Radiol Anat, 34: 935-941.

4. Capaccioli L, Stecco A, Vanzi E, Brizzi E (2000) Ultrasonographic study on the growth and dimensions of healthy children and adult organs. Int J Anat Embryol, 105: 1-50.

5. Chowdhury Al, Sultana SZ, Mannan S (2012) Morphometric study of splenic volume in Bangladeshi cadaver. Mymensingh Med J, 21: 445-449.

6. Cruz-Orive LM (1997) Stereology of single objects. J Microsc, 186: 93-107.

7. De La Grandmaison GL, Clariand I, Durigon M (2001) Organ weigh in 684 adult autopsies: new tables for a Caucasoid population. Forensic Sci Int, 119: 149-154.

8. Ehimwenma O, Tagbo MT (2011) Determination of normal dimension of the spleen by ultrasound in an endemic tropical environment. Niger Med J, 52: 198-203.

9. Geraghty EM, Boone JM, Mcgahan JP, Jain K (2004) Normal organ volume assessment from abdominal CT. Abdom Imaging, 29: 482-490.

10. Golalipour MJ, Kord H, Ghafari S, Gharravi AM, Davarian A, Fazeli SA, Azarhoush R (2008) Morphometric alterations to the rat spleen following formaldehyde exposure. Folia Morphol, 67: 19-23.

11. Harris A, Kamishima T, Hao HY (2010) Splenic volume on computed tomography utilizing automatically contouring software and its relationship with age, gender, and anthropometric parameters. Eur J Radiol, 75: e97-e101.

12. Henderson JM, Heymsfield, SB, Horowitz J, Kutner MH (1981) Measurement of liver and spleen volume by computed tomography. Radiology, 141: 525-527.

13. Hoefs JC, Wang FW, Lilien DL, Walker B, Kanel G (1999) A novel, simple method of functional spleen volume calculation by liver-spleen scan. J Nucl Med, 40: 1745-1755.

14. Hosey RG, Mattacola CG, Kriss V, Armsey T, Quarles JD, Jagger J (2006) Ultrasound assessment of spleen size in collegiate athletes. Br J Sports Med, 40: 251-254.
15. Kaneko J, Sugawara Y, Matsui Y, Makuuchi M (2008) Spleen size of live donors for liver transplantation. Surg Radiol Anat, 30: 515-518.

16. Kaneko J, Sugawara $Y$, Matsui $Y$, Ohkubo T, Makuuchi M (2002) Normal splenic volume in adults by computed tomography. Hepatogastroenterology, 49:1726-1727.

17. Konus OL, Ozdemir A, Akkaya A, Erbas G, Celik H, Isik S (1998) Normal liver, spleen, and kidney dimensions in neonates, infants, and children: evaluation with sonography. AJR, 171: 1693-1698.

18. Kvist H, Chowdhury B, Grangard U, Tylen U, Sjostrom L (1988) Total and visceral adipose-tissue volumes derived from measurements with computed tomography in adult men and women: predictive equations. Am J Clin Nutr, 48: 1351-1361.

19. Loftus WK, Chow LTC, Metreweli C (1999) Sonographic measurement of splenic length: correlation with measurement at autopsy. J Clin Ultrasound, 27: 71-74.

20. Meier JM, Alavi A, Iruvuri S, Alzeair S, Parker R, Houseni M, Hernandez-Pampaloni M, Mong M, Torigian DA (2007) Assessment of age-related changes in abdominal organ structure and function with computed tomography and positron emission tomography. Semin Nucl Med, 37: 154-172.

21. Odaci E, Sahin B, Sonmez OF, Kaplan S, Bas O, Bilgic S, Bek Y, Ergür H (2003) Rapid estimation of the vertebral body volume: a Cavalieri Principle combination of the Cavalieri principle and computed tomography images. Eur J Radiol, 48: 316-326.

22. Okoye IJ, Agwu KK, Ochie K (2005) Sonographic splenic sizes in normal adult Nigerian population. West Afr J Radio, 12: 37-43.

23. Prassopoulos P, Cavouras D (1994) CT assessment of normal splenic size in children. Acta Radiol, 35: 152-154.

24. Prassopoulos P, Daskalogiannaki M, Raissaki M, Hatjidakis A, Gourtsoyiannis N (1997) Determination of normal splenic volume on computed tomography in relation to age, gender and body habitus. Eur Radiol, 7: 246-248.

25. Rashid M, Roberts EA (2000) Nonalcoholic steatohepatitis in children. J Pediatr Gastroenterol Nutr, 30: 48-53.

26. Rodrigues AJ, Rodrigues CJ, Germano MA, Rasera JI, Cerri GG (1995) Sonographic assessment of normal spleen volume. Clin Anat, 8: 252-255.

27. Rosenberg HK, Markowitz RI, Kolberg H, Park C, Hubbard A, Bellah RD (1991) Normal splenic size in infants and children: sonographic measurements. AJR, 157: 119-121.

28. Sabatino AD, Brunetti L, Maffè GC, Giuffrida P, Corazza GR (2013) Is it worth investigating splenic function in patients with celiac disease? World J Gastroenterol, 19: 2313-2318.

29. Schulz HG, Christou A, Gursky S, Rother P (1986) Computerized tomography studies of normal morphology and volumetry of parenchymatous epigastric organs in humans. Anat Anz, 162: 1-12.

30. Spielman AL, DeLong DM, Kliewer MA (2005) Sonographic evaluation of spleen size in tall healthy athletes. AJR, 184: 45-49.

31. Yetter EM, Acosta KB, Olson MC. Blundell K (2003) Estimating splenic volume: sonographic measurements correlated with helical CT determination. AJR, 181: 1615-1620. 